\title{
Enhanced microactuation with magnetic field curing of magnetorheological elastomers based on iron-natural rubber nanocomposites
}

\author{
M P VASUDEVAN ${ }^{1,2}$, P M SUDEEP ${ }^{1,6}$, I A AL-OMARI ${ }^{3}$, PHILIP KURIAN $^{4}$, P M AJAYAN $^{5}$, \\ T N NARAYANAN ${ }^{6}$ and M R ANANTHARAMAN ${ }^{1, *}$ \\ ${ }^{1}$ Department of Physics, Cochin University of Science and Technology, Cochin 682022, India \\ ${ }^{2}$ Department of Physics, Sree Sankara Vidya Peetom College, Valayanchirangara, Cochin 683556, India \\ ${ }^{3}$ Department of Physics, Sultan Qaboos University, Muscat, P.O. Box 36, Code 123, Oman \\ ${ }^{4}$ Department of Polymer Science and Rubber Technology, Cochin University of Science and Technology, Cochin 682022, India \\ ${ }^{5}$ Department of Materials Science and Nanoengineering, Rice University, Houston, TX 77005, USA \\ ${ }^{6}$ TIFR Centre for Interdisciplinary Sciences, Hyderabad 500075, India
}

MS received 29 January 2014; revised 11 August 2014

\begin{abstract}
The incorporation of nanoparticles of iron in a natural rubber matrix leads to flexible magnetorheological (MR) materials. Rod-shaped MR elastomers based on natural rubber and nanosized iron have been moulded both with and without the application of an external magnetic field during curing. These MR elastomer rods and filler material were characterized by X-ray powder diffraction, scanning electron microscopy and transmission electron microscopy. Magnetic properties were investigated by using vibrating sample magnetometry. Microactuation studies were carried out by employing a laser Doppler vibrometer. It is seen that microactuation of field cured samples have been enhanced by two times when compared with that of zero field cured samples. The effect of alignment of magnetic particles during field-assisted curing was also studied by using a dynamic mechanical analyzer. A plausible model is put forwarded to explain the observed enhancement of actuation for field cured samples.
\end{abstract}

Keywords. Smart materials; vibration; mechanical testing; nanocomposites.

\section{Introduction}

Magnetorheological (MR) elastomers, which are solid-state analogues of more familiar MR fluids, have been the subject of intensive research for the last few years in the leading automobile research laboratories all over the world. ${ }^{1-3}$ MR elastomers represent a new class of engineering materials known as smart materials, and are viscoelastic solids whose material properties can be tuned by an external magnetic field. The important properties of MR elastomers are actuation effect, sensing effect and the change in shear modulus. Thus these materials have potential applications in the form of actuators, transducers, automobile suspension system, clutches, breaks, vibration isolators and dampers. ${ }^{4}$

Rubber-based MR elastomers are thought to be important because composites of rubber are already employed as bushing and engine mounts. ${ }^{5}$ Moreover the apparent stiffness and damping of the composite containing rubber and magnetic filler can be tuned by applying an external magnetic field. The multiple stiffness property of MR elastomers makes them unique for elastomer-based engine parts and devices. ${ }^{6}$ The applied magnetic field can produce magnetic dipolar interaction ${ }^{7}$ between the magnetic particles and hence induce changes in the stiffness and damping. ${ }^{8}$ By varying the magnetic field, the stiffness of the composite can be altered. Such

\footnotetext{
*Author for correspondence (mraiyer@yahoo.com)
}

MR devices in a feedback control mechanism can serve as an active vibration arrestor. The size of filler element also has a profound influence in determining the stiffness of the resulting elastomer. It is well known that the incorporation of ferromagnetic/ferrimagnetic fillers impart magnetic properties to a matrix and the performance characteristics of the composite can then be tailored by controlling the volume fraction. With the advent of nanoscience and nanotechnology nanosized fillers are extensively being used which not only impart the required magnetic properties, but also enhance the mechanical properties of the composite. This is called the size effect on the mechanical properties when compared with the micron-sized counterparts. ${ }^{9}$ Thus, with the incorporation of nanosized iron into a polymer matrix of the type natural rubber, is aimed at achieving the twin advantages namely, imparting the required magnetic properties to the matrix and also enhancing the mechanical property of the resulting composite. Literature pertaining to nanocomposites based on iron and natural rubber are rather scarce. Moreover an attempt to fabricate a MR microactuator with nanosized iron as filler assumes significance since this is a low-cost alternative to metals like cobalt and nickel. The incorporation of nanosized fillers results in flexible and mouldable components and is attractive from a practical point of view. From a fundamental perspective the modification of stiffness and microactuation with respect to field curing also 
assumes significance. This is the motivation of the present investigation.

In the recent past, several reports have been published on MR materials based on synthetic rubber. ${ }^{10-13}$ Natural rubber has advantages over other synthetic materials due to its abundant availability in the state of Kerala and inexpensive production techniques. Moreover, casting and moulding of natural rubber into complex shapes is easy. The nature and amount (loading) of magnetic filler materials have unique roles in the resulting properties of MR elastomers. Considering the key parameters for a good quality MR elastomer, the assortment (soft/hard) of the magnetic filler is also important in designing an MR-based device.

Various microactuators based on silicon, Ti-Ni thin films and carbon nanotubes were recognized in the recent past for various micro-electro-mechanical devices. ${ }^{14-17}$ These devices were realized using various sophisticated lithographic and deposition techniques and most of them work in the 'contact-mode'. Attempts to make MR elastomer-based microactuator devices had met with only little success. ${ }^{18}$ Because of high magnetic permeability, low remanent magnetization and high saturation magnetization, iron particles are used as fillers for MR elastomers and thus it provides high interparticle attraction and produce large MR effect. In the present investigation, iron-based MR elastomers have been fabricated using a modified curing technique. Iron powder was milled for $10 \mathrm{~h}$ in a high-energy ball milling unit to reduce size. A non-contact method employing the laser Doppler vibrometric technique has been adopted to investigate the microactuation of polymer rod. A microactuator based on these MR rods has been realized and tested. The effect of applied voltage and frequency on microactuation of MR elastomer rods is also investigated.

\section{Experimental}

\subsection{Design and fabrication of the mould and coil}

A homemade mould (figure 1a) is used for fabricating cylindrical MR elastomer rods. The material used for the mould is stainless steel which is nonmagnetic. The mould consists of three parts (a) platform (base) $(12 \mathrm{~cm}$ diameter and $2.5 \mathrm{~cm}$ height), (b) central cylindrical portion (11.6 cm diameter) of

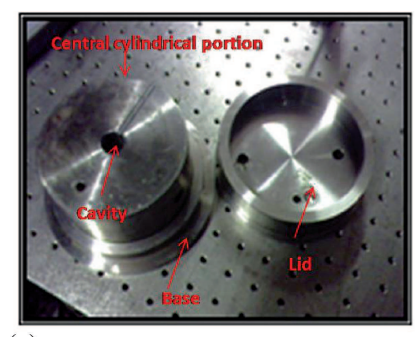

(a)

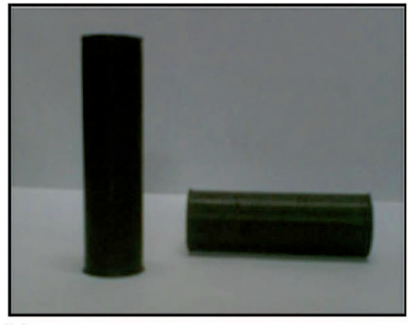

(b)
Figure 1. (a) Photograph depicting the homemade mould for fabricating MR elastomer rods and (b) MR elastomer rod. same length as that of the rod and (c) a lid (16.5 cm diameter, $4.4 \mathrm{~cm}$ height). The mould has a cylindrical cavity of having a length of $60 \mathrm{~mm}$ with a diameter of $18 \mathrm{~mm}$ for inserting the test sample for curing.

A specially designed coil (solenoid, 1000 turns maximum field $\sim 0.1 \mathrm{~T}$ ) is used to generate the required magnetic field during curing process for alignment of iron $(\mathrm{Fe})$ particles. The coil was wound over an asbestos cement (AC) pipe with fibre glass coating. AC pipe and fibre glass coating can protect the insulation of the winding wires. Gauge of wire used is $20 \mathrm{SWG}$. The term infield curing is used to indicate the employment of an appropriate magnetic field during the curing of the samples. This is a set-up fabricated in house consisting of an electromagnet with provision to increase/ decrease the current passing through the coil. This set-up exactly fits in between the curing set-up. MR elastomer rods having a diameter of $1.8 \mathrm{~cm}$ and length of $6 \mathrm{~cm}$ are fabricated using this set-up (figure $1 b$ ).

\subsection{High energy ball milling (HEBM)}

$\alpha$-Fe powder was purchased from Laboratory Rasayan (s.d. Fine-Chem Ltd. BOISAR 401501, iron (metal) powder, electrolitic-300 mesh $(84.67 \mu \mathrm{m})$ LR, Product No. 38601) and using a Fritsch Planetary micromill 'Pulverisette 7' highenergy ball mill, iron powder was milled for $10 \mathrm{~h}$ to reduce the size of the particles.

\subsection{Mixing and moulding}

MR elastomers are fabricated for a loading of $20 \mathrm{phr}$ (parts per $100 \mathrm{~g}$ of rubber) which means that $20 \mathrm{~g}$ of the filler (iron) is mixed with $100 \mathrm{~g}$ of rubber along with ingredients for mixing. This was carried out in accordance with a recipe given in table 1. The mixing of the ingredients was carried out in a Brabender Plasticorder. The homogenization of the mixture was achieved by means of a two roll mixing mill. After proper mixing and homogenization of the mixture, this was aged for $24 \mathrm{~h}$ and a small sample piece is cut from the sheet for cure time determination. The cure characteristics of the compound was determined using a rubber processing analyzer (RPA). In RPA sample is placed within a chamber maintained at a temperature of $150^{\circ} \mathrm{C}$ and a pressure of $18 \mathrm{MPa}$. Vulcanization is determined by the increase in the torque required to maintain given amplitude of oscillation at

Table 1. Recipe for the fabrication MR elastomer.

\begin{tabular}{lc}
\hline Ingredients & Quantity (g) \\
\hline Natural rubber & 100 \\
Zinc oxide & 4 \\
Stearic acid & 3.2 \\
Triphenyl quinone (TQ) & 1 \\
N-cyclohexyl benzthiazyl sulphenamide (CBS) & 1 \\
Sulphur & 2.5 \\
Filler (iron) & 20
\end{tabular}


a given temperature. The torque is proportional to low strain modulus of elasticity. The torque is plotted against time to obtain the cure characteristics of the sample (figure 2). MR rods were cured/moulded based on the cure time evaluated from such experiments. Samples are cured at $150^{\circ} \mathrm{C}$ for 30 35 min (depending on the filler concentrations and length of the rod). A field of 250 Gauss was applied during curing.

\subsection{Characterization}

The structural characterization of MR elastomer rods were carried out using an X-ray powder diffraction (XRD, Rigaku Dmax-C), with $\mathrm{Cu} \mathrm{K} \alpha$ radiation $\lambda=1.5418 \AA$ and morphology was examined using scanning electron microscope (FEI Quanta 400 ESEM). Transmission electron microscopy

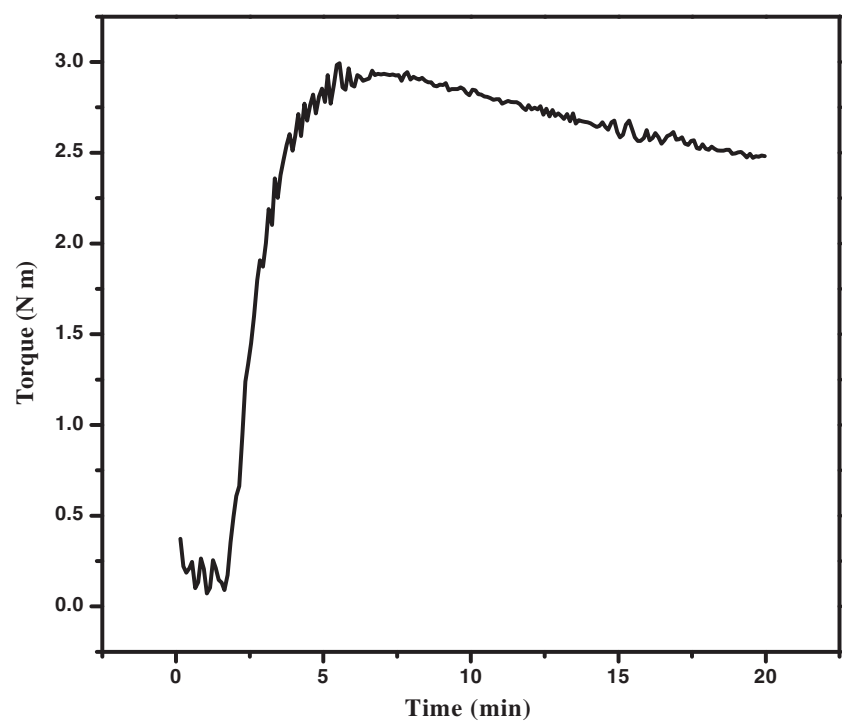

Figure 2. Cure characteristics of $20 \mathrm{phr}$ iron-NR composite.
(JOEL JEM 2200 FS) was used to determine the size of the milled Fe particles. Magnetic properties of these MR rods were studied using a vibrating sample magnetometer (VSM, model: DMS 1660). Dynamic mechanical tests were performed on samples using an Instron Electropuls E3000 instrument and Wavematrix software.

\subsection{Microactuation measurements using laser Doppler vibrometer $(L D V)$}

Microactuation measurements were carried out using the LDV (OFV-5000 with OFV-505 Sensor Head, PolyTec) in the noncontact mode. A schematic of the experimental set-up using LDV is shown in figure 3. LDV measures the velocity and absolute displacement of the fabricated MRE rods.

\section{Result and Discussion}

\subsection{Structural and morphological studies}

Figure $4 \mathrm{a}$ and $\mathrm{b}$ depicts the XRD pattern of $10 \mathrm{~h}$ ball milled $\mathrm{Fe}$ and $\mathrm{Fe}$ nanoparticles in natural rubber. Iron is found to be in the body centered cubic phase with a lattice parameter of $1.45 \AA$. Crystallite size evaluated from Debye-Scherrer formula ${ }^{19}$ is found to be $\sim 12 \mathrm{~nm}$. Figure 5 a demonstrates the TEM image of $10 \mathrm{~h}$ milled Fe nanoparticles with size of $\sim 10$ $\mathrm{nm}$. The surface morphology of Fe filled natural rubber (MR elastomer) is depicted in figure $5 \mathrm{~b}$. The bright spots indicate the formation of filler cluster (iron particles) in the natural rubber matrix.

\subsection{Magnetization studies}

In order to study the magnetic poling effects during fieldassisted curing, longitudinal and transverse $M-H$ studies

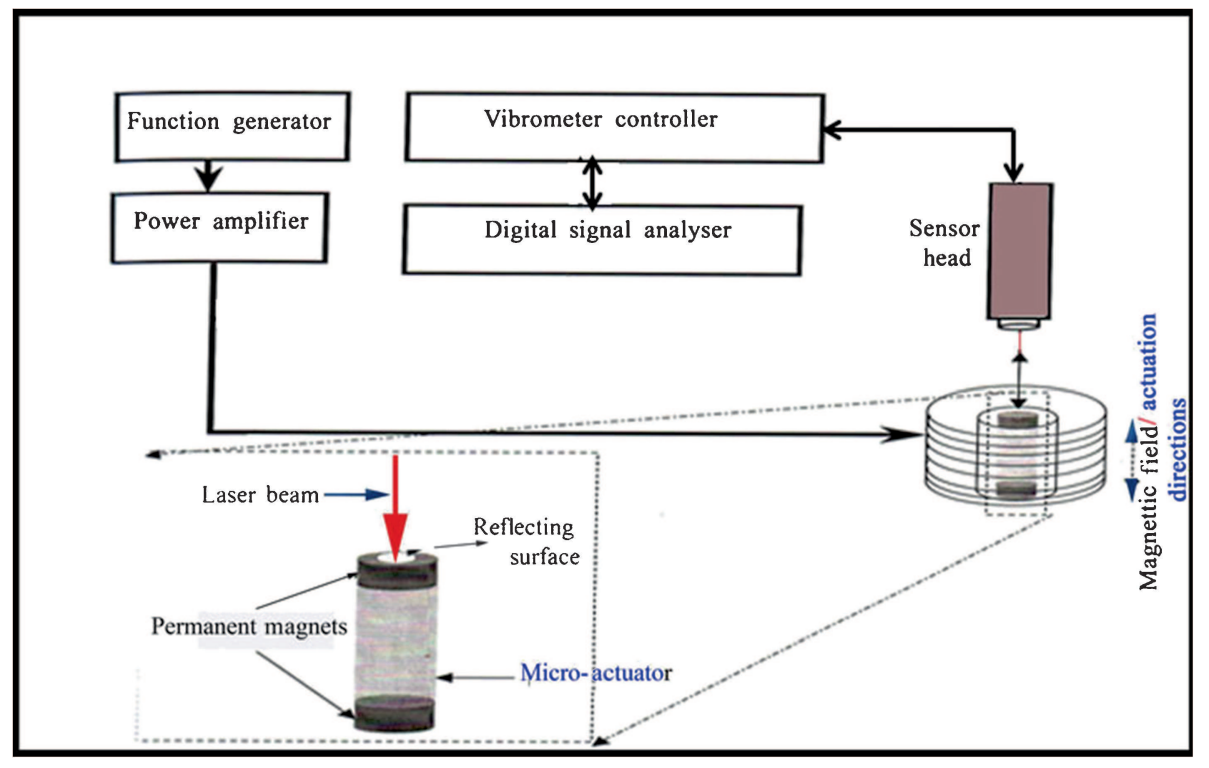

Figure 3. Schematic of the microactuation measurement using LDV. 

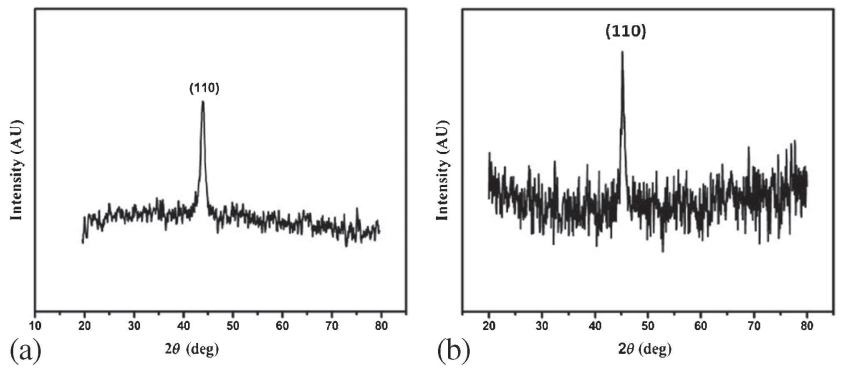

Figure 4. XRD pattern of $10 \mathrm{~h}$ ball milled (a) $\mathrm{Fe}$ and (b) $\mathrm{Fe}$ nanoparticles in natural rubber.

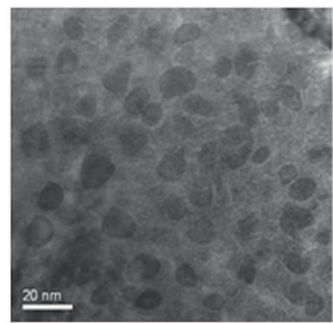

(a)

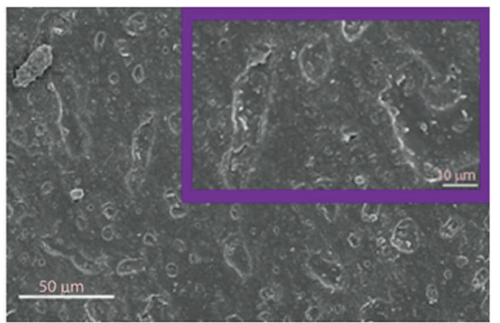

(b)
Figure 5. (a) TEM image of $10 \mathrm{~h}$ milled Fe nanoparticles and (b) SEM image of Fe filled natural rubber.

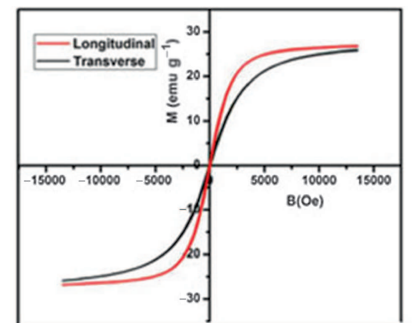

(a)

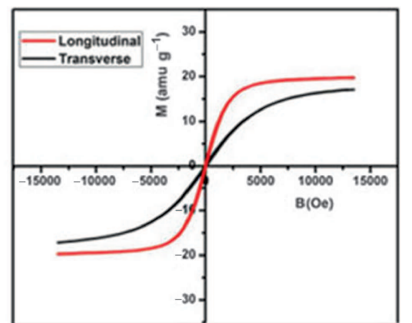

(b)
Figure 6. Magnetic hysteresis loop of MR elastomers embedded with $10 \mathrm{~h}$ ball milled Fe samples cured (a) with field and (b) without field.

were carried out. Figure 6 shows the room temperature magnetization of MR rods cured with and without the application of a magnetic field.

$M(H)$ behaviour of longitudinal and transverse fields indicates the difference in anisotropy ${ }^{20}$ in each direction. A higher anisotropy in transverse direction is mitigating the alignment of filler iron particles in one particular direction. This is also clearly visible in the scanning electron micrograph. Thus, magnetization studies points to the alignment of filler particles when they were cured under an applied magnetic field.

\subsection{Microactuation studies}

Figure 7 shows the results of microactuation studies carried out on Fe filled MR elastomers using LDV. Microactuation studies were conducted on both samples which are cured with and without the application of a magnetic field. The dynamic response of the MR rod was studied by changing the ac drive voltage of the coil. The measurements were carried out at two pre-amplified drive voltages of 20 and $30 \mathrm{mV}$ as shown in figure 7. This illustrates the effect of ac field

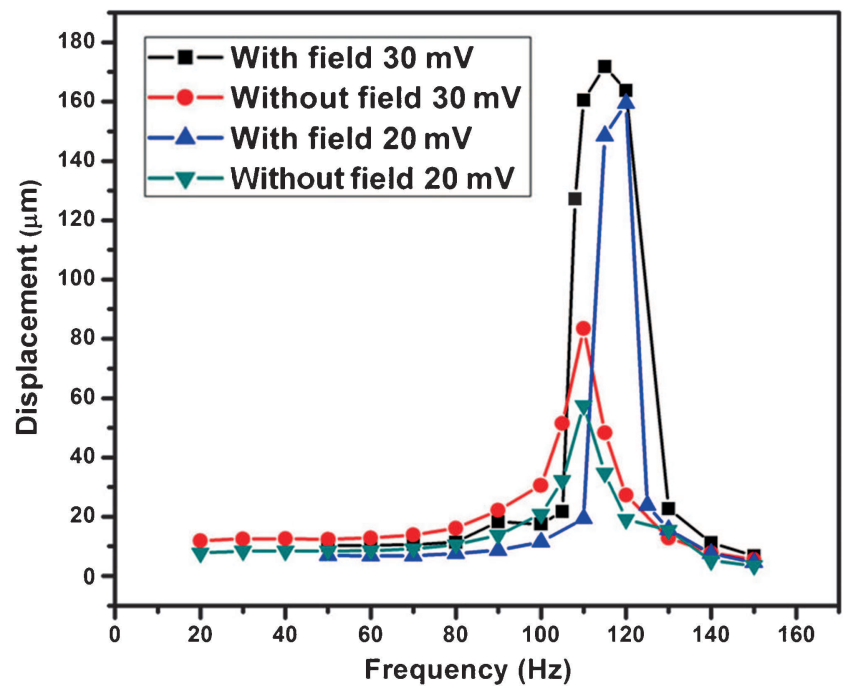

Figure 7. Displacement vs. frequency curve of MR elastomers cured with and without magnetic field.

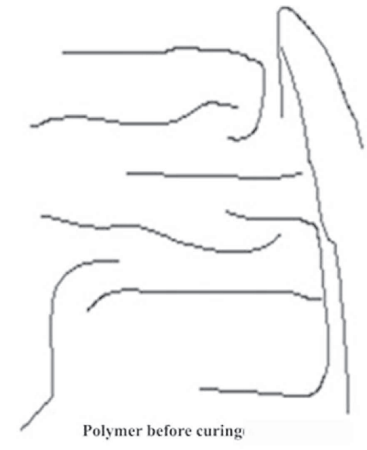

(a)

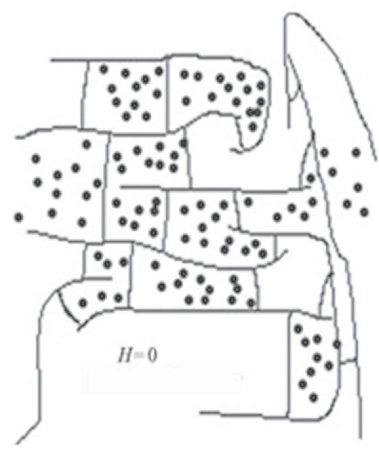

(c)

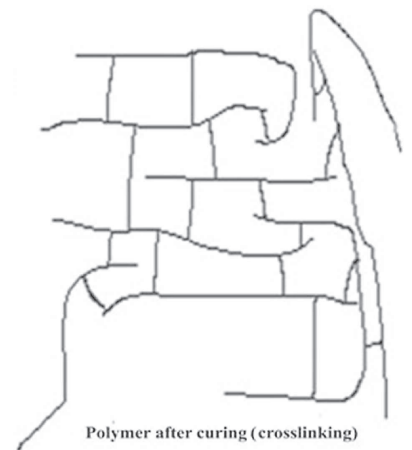

(b)

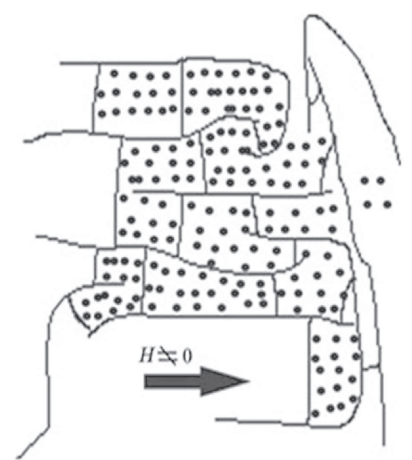

(d)
Figure 8. Schematic representation of magnetic filler particles in an MR elastomer matrix. (a) Natural rubber, (b) elastomer, (c) elastomer with non-aligned magnetic filler and (d) elastomer with aligned magnetic filler. 
on the displacement. The displacement of the elastomer is enhanced with increase in ac voltage because of the larger magnetic field produced. The displacement in the case of a sample cured under an applied magnetic field is much higher than (2 times) that of a sample cured without field. This clearly establishes the alignment ${ }^{21}$ of filler particles during field curing. As the particles become aligned, the magnetic interaction $^{22}$ between the fillers enhances the displacement.

Effect of magnetic alignment of filler particles in microactuation $^{23}$ is schematically represented in figure 8. Polymer chains ${ }^{24}$ have a usual tendency to slip away on the application of a force (figure 8a). This can be controlled by cross linking the polymer chains (figure $8 \mathrm{~b}$ ). The filler material trapped between the polymer chains further restricts this motion. However these filler materials are randomly oriented in the matrix (figure 8c). The application of an external magnetic field while curing tends to align the initial random magnetization vectors of the filler particles along the direction of the applied field (figure 8d). As a result the interparticle attractive magnetic forces reduce the average particle distance. SEM of samples cured with and without the application of a magnetic field also supports the above observation (figure 9).

The interaction between the magnetic nanoparticles in the polymer matrix is almost negligible as the superparamagnetic nature of the filler is also reflected in the composites (figure 6). The frequency at which the maximum displacement is observed, in this measurement is quite different from that reported in the earlier works. ${ }^{25-27}$ This frequency is related to the applied frequency in the dynamic magnetizing coil system, indicating theresponse of the microactuator with the applied frequency.

Figure 10a and b confirms the effect of alignment and enhancement of actuation. Figure 10a shows displacementfrequency curve for with field (WF) and without field (WOF) cured samples at a driving voltage of $30 \mathrm{mV}$. The effect of alignment in the WF sample is clear from the enhancement in the displacement by an order of two compared with WOF. Since the alignment modifies the stiffness and a frequency shift was also observed. The same effect, although relatively less, can be seen when the coil was driven by $20 \mathrm{mV}$ (figure 10b) substantiate the effect of alignment. MR elastomers (MREs) cured under field on condition can give enhanced microactuation properties and thus they can find immense applications in various fields such as automobiles, aerospace, defence and also as seismic dampers. The viscoelastic properties of these MR elastomers can be tuned in accordance with the application of an alternating magnetic field.

Figure 11 illustrates the comparison of stiffness of the samples cured with magnetic field and without field in different filler concentrations. The measurement was carried out
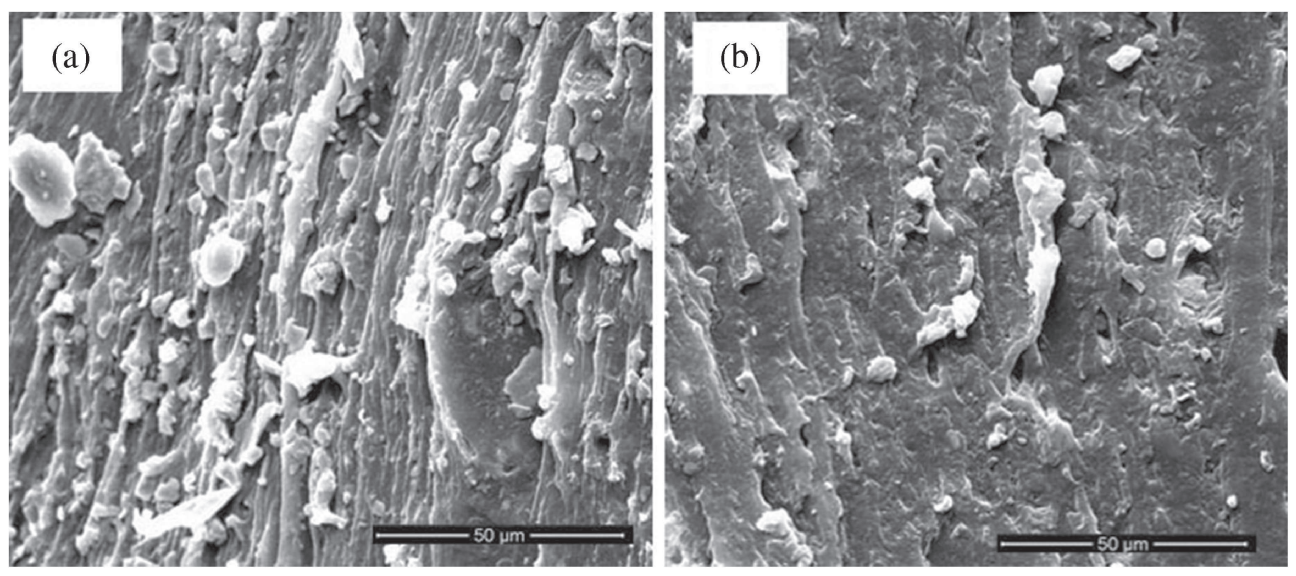

Figure 9. SEM images of natural rubber-iron nanocomposites cured (a) with field and (b) without field.
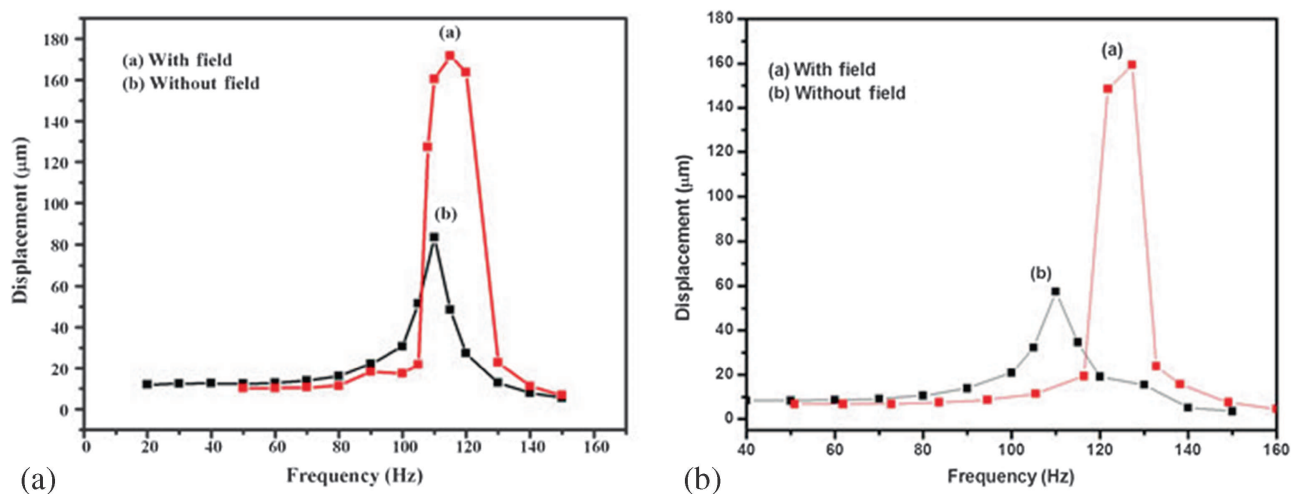

Figure 10. Variation in displacement of MR rods with frequency for drive voltages (a) 30 and (b) $20 \mathrm{mV}$. 


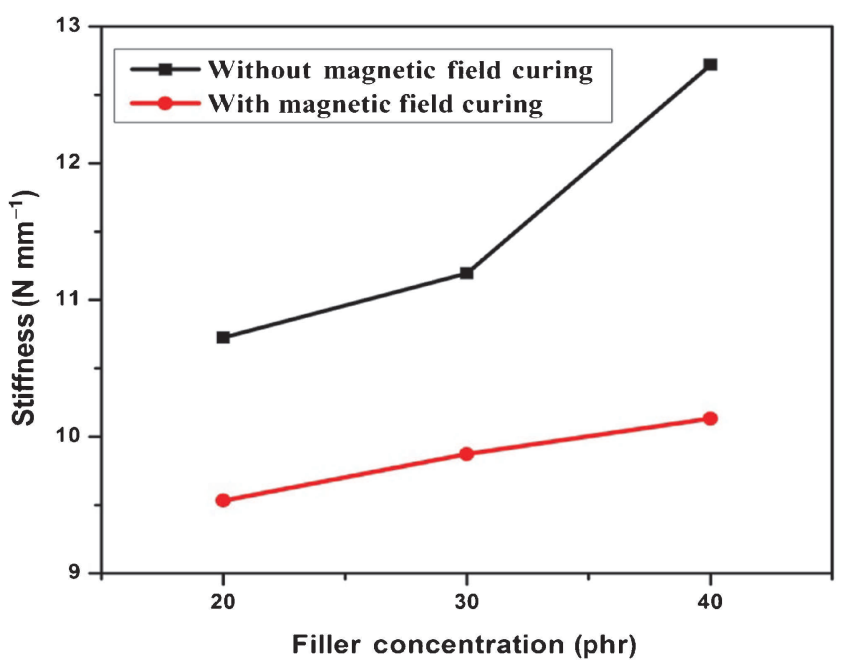

Figure 11. Variation of stiffness with filler concentration for the MR elastomers cured (a) without field and (b) with field.

using Instron mechanical analyzer. A decrement in stiffness can be clearly seen in the infield cured sample which again correlates the results obtained from the microactuation measurements using LDV. It is found that the actuation produced by field cured samples is superior when compared with samples cured without the presence of magnetic field. It may be noted that this is a compression-based DMA and to substantiate the above conclusion, we need to conduct shearbased tests using DMA. Field-assisted curing help align magnetic particles along the direction of the applied magnetic field which is along the length of the MR rod. This in effect is equivalent to polling or a permanent bias and any small applied magnetic field on the cured samples during actuation produces an enhanced displacement. However, it is hard to correlate the decrease in stiffness with increase in microactuation with the available data. Some more experiments are necessary to substantiate the above findings.

\section{Conclusions}

A MR microactuator based on nanosized iron and natural rubber has been successfully fabricated. Microactuation studies have been carried out using a noncontact method employing LDV. Effect of polling on MR rods was studied and the field cured MR rods exhibited an enhanced microactuation when compared with the zero field cured MR rods. A plausible model has been put forward to explain the observed enhanced microactuation. Magnetic field-assisted curing of elastomers enhances actuation and these MR elastomers can be directly used in vibration arrestors and controllers among others.

\section{Acknowledgements}

MP Vasudevan acknowledges UGC, New Delhi, for teacher fellowship. MRA and PMS acknowledge DAE-IREL (File
No. IRELTDC/SAO/08-09/3) for financial assistance. PMS acknowledges UGC, Government of India, for the financial assistance through the research fellowship in sciences for meritorious students (RFSMS).

\section{References}

1. Jolly M R, Carlson J D and Munoz B C 1996 Smart Mater. Struct. 5607

2. Wang Z L and Kang Z C 1998 Functional and smart materials structural evolution and structure analysis (New York: Plenum Publishing Corp)

3. Chen L, Gong X-L and Li W H 2007 Smart Mater. Struct. 16 2645

4. Chen L, Gong X-L, Jiang W-Q, Yao J-J, Deng H-X and Li W-H 2007 J. Mater. Sci. 425483

5. Davis L C 1999 J. Appl. Phys. 853348

6. Ginder J M, Nichols M E, Elie L D and Clark S M 2000 Proc. SPIE-Int. Soc. Opt. Eng. 4183985

7. Martin J E, Venturini E, Odinekv J and Anderson R A 2000 Phys. Rev. E 612818

8. Zhou G Y 2003 Smart Mater. Struct. 12139

9. Farshad M and Benine A 2004 Polym. Test. 23347

10. Lokander M and Stenberg B 2003 Polym. Test. 22677

11. Li J F and Gong X-L 2008 J. Cent. South. Univ. Technol. 15 261

12. Li W H, Zhou Y and Tian T F 2010 Rheol. Acta 49733

13. Yang Y, Li H and Kang B-S 2007 J. Cent. Univ. Technol. s1 263-03

14. Tabid-Azar M 1990 Nanotechnology 181

15. Tsuchiya K and Davies S T 1998 Nanotechnology 967

16. Ashrafi B, Hubert P and Vengallatore S 2006 Nanotechnology 174895

17. Thomas S, Mathew J, Radhakrishnan $\mathrm{P}$, Nampoori V P N, George A K, Al-Harthi S H, Ramanujan R V and Anantharaman M R 2010 Sens. Actuators A: Phys. 16283

18. Snyder R L, Nguyen V Q and Ramanujan R V 2010 Smart Mater. Struct. 19055017

19. Sunny V, Narayanan T N, Sajeev U S, Joy P A, Sakthi Kumar D, Yoshida Y and Anantharaman M R 2006 Nanotechnology 174765

20. Kowski A B and Kaczkowski Z 2000 J. Magn. Magn. Mater. 216234

21. Kankanala S V and Triantafyllidis N 2004 J. Mech. Phys. Solids $\mathbf{5 2} 2869$

22. Kallio M 2005 The elastic and damping properties of magnetorheological elastomers (VTT Publications) p 565

23. Bellen C and Bossis G 2002 Int. J. Mod. Phys. B 162447

24. Blow C M and Hepburn C 1982 Rubber technology and manufacture (Butterworth Scientific) 2nd edn

25. Germano R, Ausanio G, Iannotti V, Lanotte L and Luponio C 2000 Sens. Actuators A: Phys. 81134

26. Germano R and Lanotte L 1997 Sens. Actuators A: Phys. 59 337

27. Ausanio G, Iannotti V and Lanotte L 2009 Sens. Actuators A: Phys. 153162 